\title{
Monitoria inclusiva no curso de odontologia em tempos de COVID-19: um relato de experiência
}

\author{
Inclusive monitoring in the dentistry course in COVID-19 times: an experience report \\ Seguimiento inclusivo en el curso de odontología en COVID-19 times: un informe de experiencia
}

Recebido: 11/10/2021 | Revisado: 17/10/2021 | Aceito: 18/10/2021 | Publicado: 20/10/2021

Felipe Ferreira de Sousa ORCID: https://orcid.org/0000-0001-7015-7044 Universidade Federal de Campina Grande, Brasil E-mail: felipeufcg19.2@gmail.com

Abrahão Alves Oliveira Filho ORCID: https://orcid.org/0000-0002-7466-9933 Universidade Federal de Campina Grande, Brasil E-mail: abrahao.alves@ professor.ufcg.edu.br Igor da Silva Soares ORCID: https://orcid.org/0000-0002-7173-5675 Universidade Federal de Campina Grande, Brasil

E-mail: igor.soares@estudante.ufcg.edu.br

Misma Taihara Ramos de Oliveira ORCID: https://orcid.org/0000-0003-1774-6688 Universidade Federal de Campina Grande, Brasil E-mail: mismaoliveira.mt@gmail.com

\begin{abstract}
Resumo
A monitoria inclusiva é entendida como sendo um processo de ensino e aprendizagem que contribui de maneira ativa efetiva para a formação de modo integral do graduando com foco nas atividades de ensino, pesquisa e extensão oferecidas pelo curso. Diante do exposto, o presente artigo de cunho descritivo, de classificação relato de experiência, tem como principal objetivo descrever as vivências da monitoria inclusiva realizadas na Universidade Federal de Campina Grande. Durante a monitoria inclusiva o discente foi acompanhado durante a realização das provas e atividades, além dos encontros síncronos semanais. Portanto, é importante deixar claro que houve a troca de saberes com ganhos positivos pelas duas partes, sendo uma experiência indispensável por possibilitar a vivência de forma concreta das práticas pedagógicas.
\end{abstract}

Palavras-chave: Monitoria inclusiva; Odontologia; Relato de experiência.

\begin{abstract}
Inclusive monitoring is understood as being a teaching and learning process that actively contributes to the integral formation of the undergraduate, focusing on the teaching, research and extension activities offered by the course. Given the above, this descriptive article, classified as experience report, has as its main objective to describe the experiences of inclusive monitoring carried out at the Federal University of Campina Grande. During the inclusive monitoring, the student was accompanied during the tests and activities, in addition to the weekly synchronous meetings. Therefore, it is important to make it clear that there was an exchange of knowledge with positive gains by both parties, being an indispensable experience for enabling the experience of pedagogical practices in a concrete way.
\end{abstract}

Keywords: Inclusive monitoring; Dentistry; Experience report.

\footnotetext{
Resumen

El seguimiento inclusivo se entiende como un proceso de enseñanza y aprendizaje que contribuye activamente a la formación integral del pregrado, enfocándose en las actividades de docencia, investigación y extensión que ofrece el curso. Dado lo anterior, este artículo descriptivo, catalogado como relato de experiencia, tiene como objetivo describir las experiencias de monitoreo inclusivo realizadas en la Universidad Federal de Campina Grande. Durante el seguimiento inclusivo, el alumno estuvo acompañado durante las pruebas y actividades, además de las reuniones sincrónicas semanales. Por tanto, es importante dejar claro que hubo un intercambio de conocimientos con ganancias positivas por parte de ambas partes, siendo una experiencia indispensable para posibilitar la vivencia de prácticas pedagógicas de manera concreta.
}

Palabras clave: Monitoreo inclusivo; Odontología; Informe de experiencia. 


\section{Introdução}

Durante a graduação em Odontologia, os estudantes brasileiros têm uma formação baseada na teoria, dentro da sala de aula, e em atividades práticas, também em laboratórios, procedimentos pré-clínicos e em atendimento clínico. Mas, nem todos os alunos conseguem compreender de forma satisfatória todos os conteúdos teóricos e práticos que são exigidos e trabalhados pelos docentes em sala de aula, se fazendo necessário um suporte extra que dentro do ambiente acadêmico ganha o nome de "monitorias", da experiência de alunos monitores que já passaram pela matéria e obtiveram uma melhor compreensão dos conteúdos que estão sendo trabalhados (de Melo, 2021; Garelli,2021).

A experiência da monitoria é ofertava nas universidades estaduais, federais, públicas e privados de forma optativa, voltada aos alunos que encontram-se em períodos adiantados dentro do percurso de formação, aos que têm habilidades e afinidade por disciplinas de modo específico, dessa forma, fazendo com que o aluno torne-se responsável pela prestação deste tipo de assistência aos alunos que encontram-se matriculados em períodos anteriores, tendo estes monitores supervisão direta de professores (da Silva,2021; Schollaert,2021).

Nesse sentido, a experiência da monitoria acadêmica revela-se como sendo uma prática de extrema importância durante o período de graduação, sendo a experiência relevante, por a mesma apresentar e representar há possibilidade da fixação e efetivação do processo de ensino e aprendizagem, no referente às práticas do discente e docente (Rodriguero,2021; Oliveira,2019).

A monitoria é entendida como sendo um processo de ensino e aprendizagem que contribui de maneira ativa e efetiva para a formação de modo integral do graduando com foco nas atividades de ensino, pesquisa e extensão oferecidas pelo curso, propiciando novas práticas e experiências no ambiente pedagógico visando o fortalecimento e associação entre a teoria e a prática com foco na integração curricular nos seus mais distintos aspectos, tendo como principal finalidade a promoção da compreensão entre alunos e professores e ofertando ao aluno a experiência de uma vivência como docente e suas atividades técnicas e teóricas (da Silva,2020; Cantin-Garside,2021; Silva,2021, do Santos,2021).

Os programas de monitoria se fazem indispensáveis dentro do ambiente universitário pois representam a possibilidade e o incentivo aos alunos a carreira da docência, e assim dando a oportunidade para que eles aprofundem seus conhecimentos nos conteúdos que são propostos nas disciplinas em que esses alunos exercem a função de monitor, oferecendo ao aluno a oportunidade de vivenciar a experiência de orientação dentro do ambiente universitário de forma mais ampla (Albuquerque,2021; Gillespie,2021; Ramos,2012; de Mesquita,2019).

Porém, diante da atual situação vivida por todos os habitantes do planeta decorrentes do atual surto da doença infectocontagiosa que recebeu o nome de COVID-19 foi necessária a realização do isolamento social, dentro do território brasileiro nos dias 17 de março do ano de 2020 o Ministério da Educação (MEC) publicou a portaria de número 343, o que permite aos institutos de ensino superior a realização de aulas presenciais com utilização de meios digitais dentro do prazo de 30 dias. Devido ao aumento significativo do número de casos em todo o mundo e em território brasileiro e a persistência da doença, o MEC, através da portaria $n^{\circ} 544$, publicada no dia 16 de junho do ano de 2020, prorrogou a vigência da portaria número 343 por período indeterminado (Chiesa,2020; Brasil,2020).

Diante da atual situação, medidas de cunho emergencial foram adotados por todas as instituições de nível superior, uma das principais foi o uso de tecnologias que possibilitem a realização das aulas de forma remota para que as atividades acadêmicas não fossem paralisadas e os graduandos prejudicados em seu processo de ensino e aprendizagem. Podendo se evidenciar a tecnologia virtual de aprendizagem (AVA), o que se caracterizou como plataformas de ensino e aprendizagem mediadoras que permitem o compartilhamento de conteúdos em tempo real (Pimenta,2021).

Nesse cenário, a Universidade Federal de Campina Grande (UFCG), utiliza a plataforma digital Google Meet e Moodle, que são ambientes virtuais de aprendizagem, tendo como uma de suas principais ferramentas o Google Meet, que 
proporciona a todos os alunos da instituição a possibilidade de acompanhar as aulas de forma remota e síncrona[L5]. Sendo importante destacar que não apenas as disciplinas obrigatórias e eletivas foram mantidas de forma remota, mas também outras atividades, dentre elas as monitorias (de Oliveira,2021).

Este artigo tem como principal objetivo descrever as vivências da monitoria inclusiva, da UFCG, por meio da utilização de tecnologias remotas Google Meet e whatsapp.

\section{Metodologia}

Assim, este artigo trata-se de um estudo descritivo do tipo relato de experiência, que foi construído-desenvolvidoelaborado a partir das experiências e percepções do autor no contexto de monitoria inclusiva. Para criação deste artigo foram utilizadas, principalmente, as memórias do autor relacionado às atividades de monitoria EAD nas disciplinas de Histologia Geral e Embriologia, Anatomia Geral e Biofísica no ano de 2021, suas posturas e as do aluno que utilizava da monitoria inclusiva retratando a importância do exercício dessa atividade como instrumento para a melhoria do ensino de graduação, através do estabelecimento de novas práticas e experiências pedagógicas.

O relato de experiência revela-se de extrema importância por permitir que seja realizada uma avaliação consistente de natureza quantitativo e qualitativo do discente regularmente matriculado, respectivamente período 2020.2 Sendo importante reafirmar a significância dessa atividade extracurricular nos centros acadêmicos (Oliveira,2020).

As disciplinas citadas integram a grade curricular do curso de graduação em Odontologia da Universidade Federal de Campina Grande (UFCG), Campus Patos/PB.São ministradas como disciplinas obrigatórias, Anatomia Geral possui 6 créditos e carga horária de 90 horas, Histologia Geral e Embriologia possui 6 créditos e carga horária de 90 horas e Biofísica 3 créditos e carga horária de 45 horas possui Tal experiência ocorreu no município de Patos/PB, no período de Fevereiro a junho de 2021, correspondendo ao semestre 2020.1, devido a paralisação das atividades acadêmicas ocorrida no início do ano 2020 que acarretou atraso no calendário acadêmico.

Coube ao monitor inclusivo acompanhar as atividades em sala de aula EAD, auxiliando o aluno; preparar materiais didáticos a serem utilizados como instrumento metodológico de ensino e estar ao lado do discente para sanar suas dúvidas sobre os diversos conteúdos teóricos oferecidos na disciplina, de modo a facilitar o processo ensino-aprendizagem.

\section{Resultados e Discussão}

\section{Relato de Experiencia}

O aluno que fez uso da monitoria inclusiva tinha 18 anos, sexo masculino, se identifica como pertencente a raça branca, morador da capital do estado da Paraíba. Estava matriculado nas disciplinas: 1- Anatomia Geral que é um componente curricular do primeiro período do curso de Odontologia da UFCG, a matéria foi dividida em parte teórica e prática todas desenvolvidas de forma online, foi realizadas 3 provas durante o semestre e uma atividade extra que consistiu em provas semanais compostas por duas perguntas, os alunos tinham 3 min para responder as questões, ao final as notas das 15 provas foram somadas gerando uma quarta nota extra. 2- Histologia Geral e embriologia também sendo componente curricular do primeiro período, as aulas foram ministradas online ao vivo via Google Meet todas as semanas. foram realizadas 30 provas, sendo 15 provas teóricas e 15 provas práticas e apresentação de 15 pranchas de imagem histológicas no decorrer do período. 3Biofísica mais uma disciplina que compõe a matriz curricular do curso, todas as aulas foram enviadas aos alunos via e-mail. Foram realizadas 3 provas e 3 atividades.

Durante os encontros foram abordados temas diversos relacionado às disciplinas, em Anatomia Geral foram os conteúdos trabalhados tinham como objetivo preparar o aluno para um conteúdo específico de anatomia que seria estudado no período seguinte em Anatomia Topográfica: Cabeça e Pescoço. Em Histologia os assuntos abordados assim como em anatomia 
geral eram base para a disciplina do período seguinte que trabalharia de maneira específica, onde a histologia seria voltada em sua totalidade para Odontologia. No referente a Biofísica todo o conteúdo abordado serve de alicerce para disciplinas obrigatórias futuras como: Fisiologia Humana e Bioquímica e Fisiologia Bucal. O aluno apresentou dificuldades acentuadas relativo a aprendizagem de duas matérias Anatomia e Histologia sendo incapaz de reconhecer uma das principais estruturas ósseas e fundamentais para o desenvolvimento das atividades futuras no curso o Osso Mandibular (a mandíbula), apresentando maior dificuldade em Histologia onde não conseguia reconhecer nem uma das estruturas apresentadas, a capacidade de reconhecer estas estruturas sendo fator indispensável para se obter um bom desempenho nestas e em futuras disciplinas. Imagens das estruturas que estavam sendo estudadas eram utilizadas nos encontros para facilitar a associação e o reconhecimento por parte do estudante, assim como outras estratégias.

Para auxiliar o aluno, o monitor enviou para o mesmo resumos e atividades de fixação do conhecimento criadas pelo monitor, as atividades consistiam em 10 perguntas de múltipla escolha, primeiro o monitor enviado às perguntas entre dois $\mathrm{e}$ três dias enviada ao aluno as respostas da atividade junto com o material de apoio que seria usado na próxima semana. Os encontros síncronos (monitoria) com o aluno aconteceram através do Google Meet onde os resumos enviados foram utilizados nos estudos, além de slides sobre o assunto que seria estudado na semana. Como resultado do trabalho desenvolvido durante o semestre o aluno obteve aprovação nas disciplinas de Anatomia Geral e Biofísica sendo reprovado na disciplina de Histologia.

A monitoria inclusiva tem importância inquestionável tanto para o monitor quanto para o aluno que utiliza dela para sanar suas dúvidas e ter um melhor aproveitamento acadêmico e de suas vivências dentro do ambiente universitário e que transcende os muros institucionais tendo impacto em sua vida fora do campus.

\section{Conclusão}

Através da experiência como monitor inclusivo o aluno adquiriu ganhos impossíveis de serem quantificados, proporcionando autonomia, o tornando ainda mais responsável, e possibilitando o seu desenvolvimento nas mais diversas áreas e suas habilidades, ganhando facilidade na retirada de dúvidas e conhecimento enquanto discente, desenvolvendo habilidades de resolução de conflitos e problemas demonstrando ao discente novos e possíveis horizontes e perspectivas acadêmicas. Sendo esta experiência extremamente proveitosa.

Por tanto com a realização deste trabalho observa-se o aumento da experiencia do aluno monitor para a inclusão de diferentes pessoas relacionado ao curso de Odontologia. Sugerindo-se a realização de novos trabalhos que visem dar visibilidade ao tipo de trabalho desenvolvido pelo monitor inclusive e os benefícios obtidos por ambas as partes.

\section{Referências}

Brasil. Portaria $n^{\circ} 544$, de 16 de junho de 2020. Substituição das aulas presenciais por aulas em meios digitais, enquanto durar a situação de pandemia do novo coronavírus COVID-19. Diário Oficial da União. 16 de junho de 2020. https: www.in.gov.br/en/ web/dou/-/portaria-n-544-de-16-de-junhode-2020261924872

Cantin-Garside, K. D., Nussbaum, M. A., White, S. W., Kim, S., Kim, C. D., Fortes, D. M., \& Valdez, R. S. (2021). Understanding the experiences of selfinjurious behavior in autism spectrum disorder: Implications for monitoring technology design. Journal of the American Medical Informatics Association, 28(2), 303-310.

Chiesa, D. (2020). A Pandemia pela COVID-19 e a Publicação em Educação Médica.

da Silva Fernandes, D. R., Diógenes, S. L. S., Sousa, I. C., \& de Souza, A. T. B. (2020). A importância da monitoria no eixo Prática Integrada Ensino Serviço e Comunidade em um curso de Medicina do Norte do Brasil. Research, Society and Development, 9(10), e3809108699-e3809108699.

da Silva Fontes, A., da Costa, E. F., da Silva, D. F., \& dos Santos, O. R. (2021). Contribuições Para O Ensino: Plataforma Moodle. Formação@ Docente, 13(2).

da Silva, T. M., dos Santos, R. L., de Oliveira, I. M. M., Júnior, J. G. D. A. S., Tavares, N. B. F., de Araújo, M. M., \& dos Santos, R. S. (2021). Vivência de monitoria acadêmica na disciplina de parasitologia humana. Revista Eletrônica Acervo Saúde, 13(7), e8289-e8289. 
Research, Society and Development, v. 10, n. 13, e522101321660, 2021

(CC BY 4.0) | ISSN 2525-3409 | DOI: http://dx.doi.org/10.33448/rsd-v10i13.21660

de Melo Costa, B. M., Lima, S. E., Campos, F. D. A. T., \& Arnaud, R. R. (2021). Tecnologia digital como ferramenta na monitoria acadêmica do curso de Odontologia em tempos de pandemia COVID-19. Revista da ABENO, 21(1), 1187-1187.

de Mesquita, G. N., Oliveira, J. G., Alves, A. L. N., da Silva, L. M. S., dos Santos Ribeiro, L. H., \& de Oliveira Silveira, T. (2019). Métodos de ensino integrados em monitoria de anatomia e Histologia: um relato de experiência. Revista Eletrônica acervo saúde, (30), e1370-e1370.

de Oliveira Teixeira, D. A., \& Nascimento, F. L. (2021). Ensino remoto: o uso do Google Meet na pandemia da COVID-19. Boletim de Conjuntura (BOCA), 7(19), 44-61.

do Santos Costa, W., Pedrosa, S. M., Sodré, G. P., Martins, J. L. R., Pereira, M. E. D., Pereira, R. A., \& da Silva, W. G. (2021). Influência das monitorias online no desempenho dos discentes na disciplina de funções vitais: relato de experiência. Anais do Seminário de Atualização de Práticas Docentes, 3(1).

Garelli, F., Rosales, N., Fushimi, E., Arambarri, D., Mendoza, L., De Battista, H., ... \& Grosembacher, L. (2021). Remote glucose monitoring platform for multiple simultaneous patients at coronavirus disease 2019 intensive care units: case report including adults and children. Diabetes Technology \& Therapeutics, 23(6), 471-473.

Gillespie, D. L., Meyers, L. A., Lachmann, M., Redd, S. C., \& Zenilman, J. M. (2021). The Experience of 2 Independent Schools With In-Person Learning During the COVID-19 Pandemic. Journal of School Health, 91(5), 347-355.

OLIVEIRA, Angelica Maciel et al. Monitoria e Necessidades Educacionais Específicas: relato de experiência. 2020.

Pimenta, E. D. S. P., da Cruz Lopes, J. B., \& da Silva Anderson, C. (2021). Ambientes Virtuais De Aprendizagem: Aspectos Relevantes Para Favorecer Um Espaço Interativo. Caminhos da Educação Matemática em Revista (Online), 11(3), 1-21.

Ramos, L. A. V., da Costa, D. S., Cascaes, J. S. A., dos Santos Souza, R. T., Rocha, I. F. C., de Sá Galeno, N., \& Cardoso, M. M. (2012). Plano de monitoria acadêmica na disciplina anatomia humana: relato de experiência. Ensino, Saúde e Ambiente, 5(3).

Rodriguero, C. R. B., Galuch, M. T. B., \& da Silva, T. D. S. A. (2021). Educação inclusiva no ensino superior e Monitoria Especial: da legalidade à educação para a sensibilidade: Inclusive education in higher education and Special Mediation: from legality to education for sensitivity. Revista Cocar, 15(32).

Schollaert, C., Alvarez, M., Gillooly, S., Tomsho, K., Bongiovanni, R., Chacker, S., ... \& Scammell, M. K. (2021). Reporting Results of a Community-Based in-Home Exposure Monitoring Study: Developing Methods and Materials. Progress in Community Health Partnerships: Research, Education, and Action, 15(1), 117-125.

Silva, K. C., \& Cavalcante, G. M. (2021). Monitoria virtual: um recurso metodológico para as aulas práticas de histologia no modelo de ensino remoto. Journal of Education Science and Health, 1(3), 1-9. 